\title{
USE OF ROBOTIC MANIPULATION SYSTEMS IN AUTOMATION OF FORGING PROCESSES
}

\author{
Jaroslav SLÁČALA, Hana ŠPAČKOVÁ, Martin MENŠíK, Petra SVOBODOVÁ, Tomáš BARČÁK \\ ${ }^{1}$ VSB - Technical University of Ostrava, Faculty of Materials Science and Technology, Ostrava, \\ Czech Republic,EU, jaroslav.slacala@vsb.cz
}

https://doi.org/10.37904/metal.2020.3662

\begin{abstract}
The introduction of a high degree of automation, such as robotic manipulation in metallurgical processes is no longer a difficult discipline with limited use although these processes are characterized by a specific environment that sets high demands on automation. Forging is a manufacturing process involving the shaping of metal using localized compressive forces where robot manipulates step by step through the forging process until the finished workpiece is removed from a forging press. In many such production lines people are still working in difficult working conditions with a high risk of injury. By replacing the worker with robots, the process becomes much safer and more efficient. Process automation in extreme environmental conditions requires a specific kind of know-how. The implementation of robots into metallurgical processes is a major challenge for robot manufacturers in terms of the robot's service life. The paper summarizes and shows the fundamental requirements that must be considered before designing and integrating robotic systems into these particular conditions.
\end{abstract}

Keywords: Automation, forging, metallurgy, robotic automation, robotics

\section{INTRODUCTION}

According to the Definition of the Oxford Advanced Learner's Dictionary word "Automation" means the use of machines and computers to do work that was previously done by people [1]. Furthermore, business process automation provides consistent, measurable and repeatable services at lower costs. Although this is an accurate academic definition, in fact automation is a broad discipline of highly sophisticated technologies appropriately combined into functional units for use in all sectors of industry from small companies to large technological units.

Metallurgy is one of the most demanding industries in terms of the working environment and therefore at the forefront of interest in the context of the introduction of robot-based automation as a substitute for human labor. It requires durability, reliability, thoughtful design, and high performance in extreme working conditions.

While industrial robots quickly establish themselves in industries such as Automotive, Metal and Machinery and Electrical / Electronics, Metallurgy, another large sector has long not been at the forefront of the work in this field. This was not due to a lack of interest in the introduction of robotics in metallurgy, but to the extreme conditions to which industrial robots are exposed.

Robotics are being used in many aspects of manufacturing to help boost productivity and efficiency while lowering production costs. Similar to the automotive industry, many robots in manufacturing replace workers to perform repetitive, monotonous, or serious and/or life-threatening tasks under the worker's guidance and control. With these robots, universality, speed and durability are valued as well as the ability to be reprogrammed for many specific tasks with varying degrees of complexities. Robotic manufacturing technologies are becoming more complex as cameras, sensors, machine vision and artificial intelligence enable robots to interact with the surrounding workspace. 
Typical products of the metallurgy that have been automated in the automotive industry includes for example gears, crankshafts, engine cases etc. With the concurrent objective of not to affect the structure and properties of the material such as hardness and straight by the automated forging processes themselves.

The key benefits of the introduction of automation:

- $\quad$ increased production volume,

- reduced labour-hours,

- reduced costs,

- improve both the effectiveness and the efficiency of processes,

- improve quality and quantity at the same time

- $\quad$ safer operation minimizing the impact of a harsh environment on a worker's health and the development of an occupational diseases.

The aim of the paper is to point out the great opportunity of robotic automation in terms of design and technical aspects of automation in metallurgical processes. The paper also provides brief information on industrial robot requirements for special uses in metallurgy. The paper further gives an example of the robotic application in the forging processes and shows that the effort is worth using a high level of robotic automation in heavy industry.

The methodologies of induction, deduction and generalization were used to obtain the outputs of the paper. This paper has been done with using interview with industry expert, system integrators and end users than associated with specific case study or academic literature research.

\section{AN INDUSTRIAL ROBOT DESCRIPTION}

Since robots are manufactured for a variety of applications, which directly affects their design, complexity and the material they are made of, this paper focuses on 6-axis industrial robots only.

Industrial robots are mechanical devices designed to replicate human-like motions of a robotic arm with a wide range of versions with various payload capacities and reaches. The robots are mostly built of steel, cast iron and aluminum. An industrial robot is an ingenious tool containing mechanical, electrical and electronic parts, as well as electrical cabling and rubber hoses. The motion-generating mechanisms such as cylinders and servo motors can be actuated by hydraulic oil, pressurized air or electricity. Hoses of silicone, rubber, and braided stainless steel connect these mechanisms to their control valves.

Electric parts as well as hydraulic or pressured actuator is controlled by the robot controller. The motion controller is an electrical cabinet located near the robot's work area. Control system software architecture integrates Robot Control, PLC Control, Motion Control and Safety Control. All controllers share a database and infrastructure.

\section{INDUSTRIAL ROBOT REQUIREMENTS FOR SPECIAL USES IN METALLURGY}

The metallurgical industry is one of the most complex and specific industries and is therefore directly destined for the introduction of the modern elements of automation. One such solution is the integration of industrial robots, however robot-based automation has its requirements and limits. Specific operating conditions such as extreme temperatures and dust are a challenge for robot manufacturers' development department to come up with new advanced solutions and use modern materials to ensure flawless performance in extreme working conditions with sustainable performance and efficiency.

Optimized industrial robots for harsh working environments are provided with a protective coating against heat, corrosion, and acid. To protect the robot from the environment, some exposed areas are covered with flexible robot jacket protective cover intended for a forge or foundry as shown in Figure 1. 


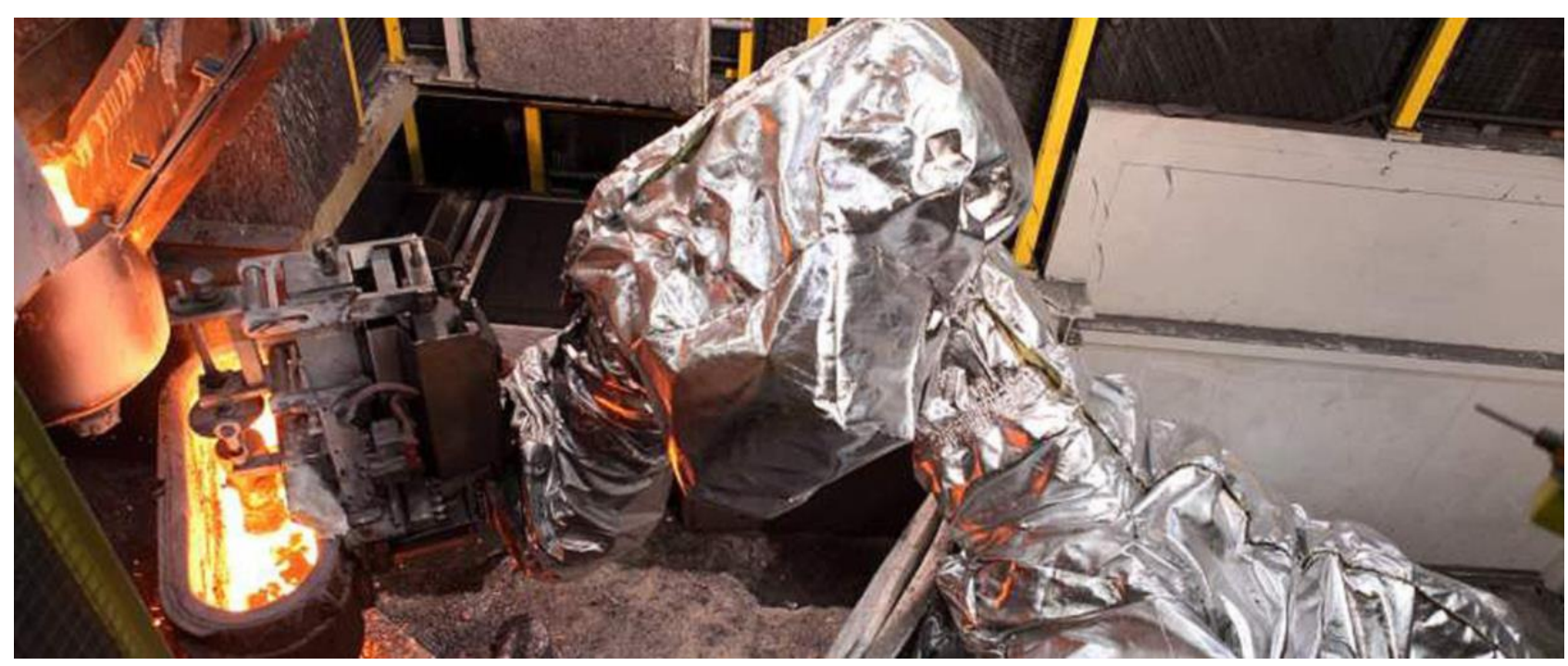

Figure 1 Robotic aluminum cover jacket that suits foundry and forging [2]

Another integral part of the robot, which is exposed to extreme conditions, is a robotic gripper. Gripping tools must withstand high temperature, therefore grippers are made of special materials in order to cope with extreme production conditions and handle parts weighing up to $300 \mathrm{~kg}$. Robot grippers are the physical interface between a robot arm and the work piece. Grippers are tailored made to meet the individual requirements of specific applications. Depending on the application, they can be operated either pneumatically, electrically or hydraulically [3]. Regardless of the type and method of operation, grippers must handle parts quickly and reliably [4-6]. As Smalcerz states in his work, during pyrometer measurement the temperature of the industrial robot arm and particularly the temperature of the gripper fingers (physical contacts) can reach more than $70{ }^{\circ} \mathrm{C}$, the adapter did not reach the temperature exceeding $45^{\circ} \mathrm{C}$, and the TCP was heated to about $35^{\circ} \mathrm{C}[7]$.

Not only the tooling, but also the robot itself must meet strict requirements. The following are the most important features that can be affected by high temperature and characterize the performance of industrial robots [8]:

- Repeatability - a measure of precision with which the robot returns to the commanded point. It is a very important feature, especially in the situations where small tolerances are required.

- Accuracy - the measure of error showing how closely the robot can reach a particular point in the working space.

- $\quad$ Reliability - one of the most important features of the robot. It is the reliability that may in some cases stop the operation of the whole production plant.

\section{INDUSTRIAL ROBOTS USED IN THE FORGING INDUSTRY}

The manufacturers need a robotic system that could operate in a harsh environment, automate material handling for three crankshaft designs, and that features simple programming and maintenance while still improving process speed and product quality.

An excellent demonstration of a robotic forging cell is shown in Figure 2. It is hot forging process of the crankshaft of the internal combustion engine of a major producer of passenger cars which is classifies as a pressure forming process. For this process, forming die tools are moved towards each other and push the material in a specific direction. 


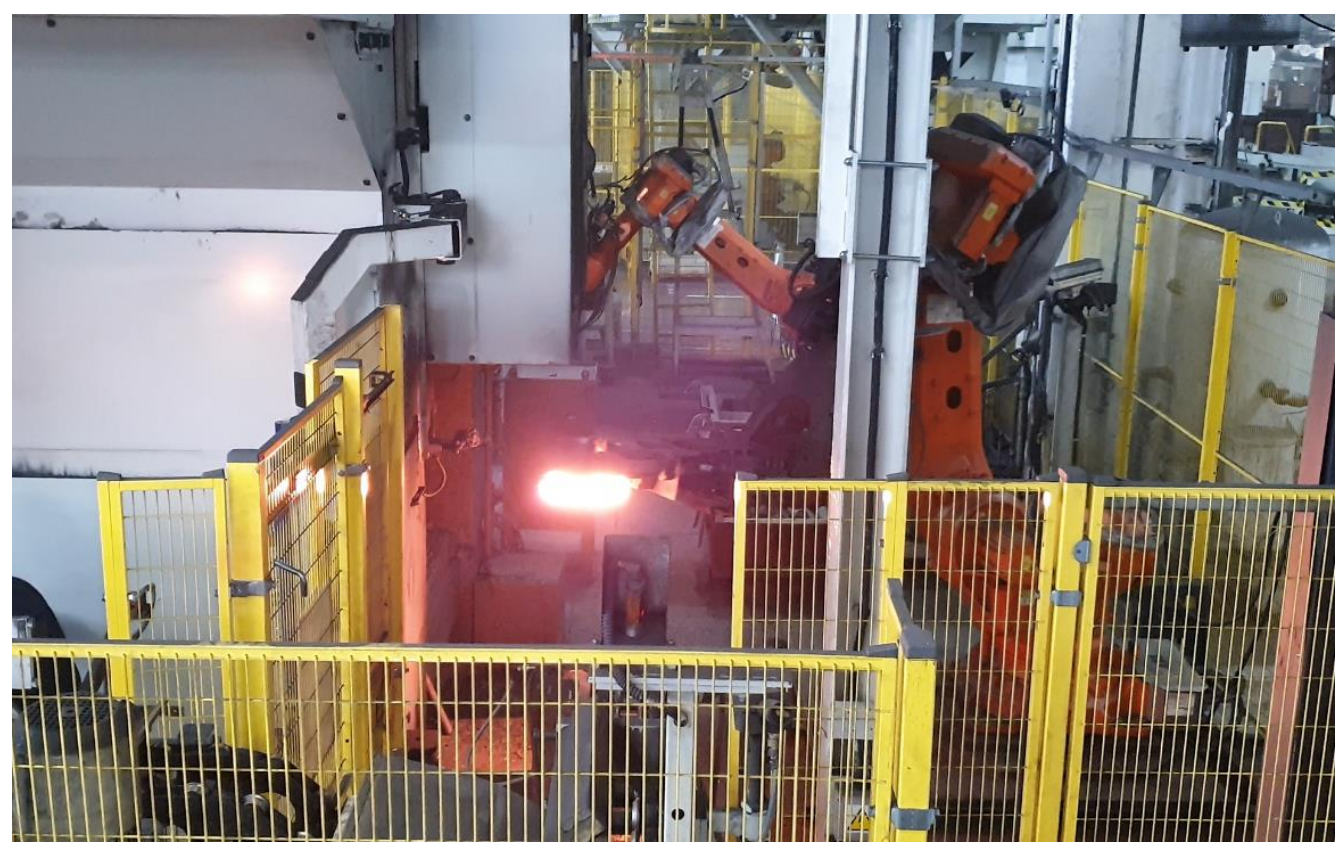

Figure 2 Industrial robot in the forge of crankshafts [own study]

It is important to have deep understanding of the processes that need to be automated in order to specify each individual task. Therefore, the cooperation of many senior experts from various branches of automation is important. These engineers bring important know-how, which ensure the smooth implementation of the automated system in compliance with the agreed deadlines and without unnecessarily increasing costs [9].
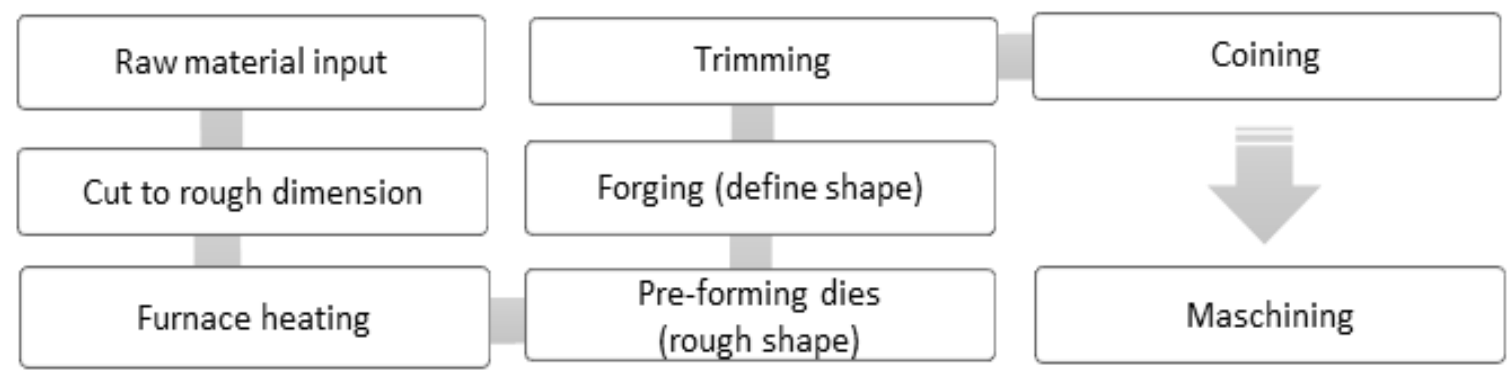

Figure 3 An individual steps of forming workpiece [own study]

In general, these individual tasks can be divided into process groups according to the specific complexity and solved individually. When solving tasks, the engineers of individual teams face various process challenges, so appropriate synergies are used. Typical forging press shop adopting automation can consist of the individual routines as shown in Figure 3:

- Task 1. Furnace heating. The material shaped and cut to the rough dimensions (billet) is heated in the furnace to the temperature of $900^{\circ} \mathrm{C}$ to $1100^{\circ} \mathrm{C}$ [10].

- Task 2. The pre-forming dies forging to get rough shape. Unloading a heated workpiece from the heating furnace and transfer it along a given robot trajectory (motion paths) to the forging die. The end effector of the robot, which is specially designed for a specific task, grips the heated raw workpiece to be processed and transfer it to the forging press in a suitable manner. Movement with the heated workpiece should start without hesitation in order to keep the temperature of the workpiece specified in the technological plan. As soon as workpiece is prepared at given place, a forging process is ready to start. This forging system uses a fully enclosed approach to co-ordinate manufacture flow. The workpiece 
handling in next steps is achieved by appropriate robots and forging presses arrangement in order to handle formed workpiece between each individual press station.

- $\quad$ Task 3. Forging to first definite forget shape.

- Task 4. Trimming process.

- $\quad$ Task 5. Coining process.

\section{CONCLUSION}

Modern metallurgical processes are constantly on the lookout for ways how to improve efficiency, increase flexibility and reduce costs. Thanks to the endeavours of the major producers of industrial robots to fulfill the needs of the market, a wide range of innovative robots appropriate for heavy operations are currently available. More and more applications are suitable for automation, thanks to the experience and rapid robots developing of big players in the field of robotics. They bring a new strength, new innovations to guarantee high efficiency to every single metallurgical process. The paper presents an overview what is meant by automation and robotics in metallurgy and describe a real application case in which the author of this work was directly involved.

\section{ACKNOWLEDGEMENTS}

\section{The work was supported by the specific university research of Ministry of Education, Youth and Sports of the Czech Republic No. SP2020/18, SP2020/61 and SP2020/136.}

\section{REFERENCES}

[1] CAMBRIDGE DICTIONARY. AUTOMATION: meaning in the Cambridge English Dictionary [online]. [viewed 2020-05-13]. Available from: https://dictionary.cambridge.org/dictionary/english/automation.

[2] The Protective Cover / Jacket For Robot [online]. [viewed 2020-05-09]. Available from: https://www.hdpr.fr/welcome/robotic-covers/.

[3] NEW.ABB.COM. Forging - ABB Robots For Foundry \& Forging Industry (Offering by Industry - Robotics) [online]. [viewed 2020-05-10]. Available from: https://new.abb.com/products/robotics/applications-by-industry/foundryforging/forging.

[4] FRISCHER, R., DAVID, J., SVEC, P., et al. Usage of analytical diagnostics whe evaluating functional surface metal defects. Metalurgija. 2015, vol. 54, no. 4, pp. 667-670.

[5] DAVID, J., VROZINA, M., NOVAKOVA, H. Control of dependability of metallurgical processes such as logistics chains. In: METAL 2012: 21st International Conference on Metallurgy and Materials. Ostrava: TANGER, 2012, pp. $1702-1708$.

[6] GARZINOVA, R., SVEC, P., FRISCHER, R. Operative control with structured data processes in steel operations environment. In: METAL 2014: 23rd International Conference on Metallurgy and Materials. Ostrava: TANGER, 2014, pp. 1647-1653.

[7] SMALCERZ, A. Aspects of Application of Industrial Robots in Metallurgical Processes. Archives of Metallurgy and Materials. 2013, vol. 58, no. 1, DOI: 10.2478/v10172-012-0174-5.

[8] ZDANOWICZ, R. Robotyzacja procesów technologicznych. Gliwice: Wydawnictwo Politechniki Śląskiej, 2002.

[9] BOCK, T., LINNER, T. Robotic Idustrialization: Automation and Robotic Technologies for Customized Component, Module, and Building Prefabrication. USA: Cambridge University Press, 2015.

[10] BOHRINGER, K.F., FEARING, K.Y., GOLDBERT, K.Y. Microassembly. In: NOF, S., eds. Handbook of Industrial Robotics, New York: Wiley, 1999, pp. 1045-1067. 